\title{
Comprometimento de servidores públicos e alcance de missões organizacionais*
}

\author{
Dulce Pires Flauzino** \\ Jairo Eduardo Borges-Andrade***
}

SumÁrio: 1. Introdução; 2. Método; 3. Resultados e discussão; 4. Conclusão.

Summary: 1. Introduction; 2. Method; 3. Results and discussion; 4. Conclusion.

Palavras-chave: comprometimento organizacional; instituições de saúde; instituições educacionais; instituições de segurança; serviço público.

KEY WORDS: organizational commitment; health institutions; educational institutions; safety institutions; public service.

O comprometer-se com a organização envolve alguma atividade do indivíduo no sentido de identificar-se com ela e desejar manter-se como seu membro, a fim de satisfazer seus interesses e facilitar o alcance das missões organizacionais. Adotando a concepção de comprometimento afetivo de Mowday, Porter e Steers (1979), que enfatiza a natureza do processo de identificação do indivíduo com os objetivos e valores da organização, e a escala reduzida proposta por Bastos (1994), este artigo analisa o comprometimento organizacional de servidores públicos ligados à atividade-fim em saúde, educação e segurança. Os resultados apontam que o instrumento

\footnotetext{
* Artigo recebido em nov. 2004 e aceito em mar. 2007. Este trabalho é parte integrante da tese de doutorado da primeira autora, tendo sido parcialmente financiado por meio de bolsa de estudos cedida pela Capes.

** Mestre e doutora em psicologia pela Universidade de Brasília (UnB) na área de psicologia organizacional e do trabalho. Professora adjunta I da Universidade Federal de Juiz de Fora, Departamento de Psicologia. Endereço: Rua Barão de Cataguases, 95, ap. 201, Centro - CEP 36015-370, Juiz de Fora, MG, Brasil. E-mail: flauzinop@uol.com.br.

$* * *$ Mestre e doutor em sistemas instrucionais pela Florida State University, Tallahassee, EUA e pós-doutor pela International Food Policy Research Institute, I.F.PR.I., Estados Unidos, pela University of Sheffield, Sheffield, Grã-Bretanha e pela Rijksuniversiteit Gröningen, RUG, Holanda. Professor titular da Universidade de Brasília, Instituto de Psicologia, Departamento de Psicologia Social e do Trabalho. Endereço: Universidade de Brasília, Instituto de Psicologia, Departamento de Psicologia Social e do Trabalho. Campus Darcy Ribeiro, ICC/Ala Sul Asa Norte - CEP 70910900, Brasília, DF, Brasil. E-mail: jeborges@linkexpress.com.br.
} 
modificado permite identificar o comprometimento dos servidores e que este está vinculado à missão organizacional percebida e não à missão real. Na amostra estudada, altos níveis de comprometimento foram encontrados entre servidores da área de segurança, quando comparada às áreas de saúde e educação.

Civil servants' commitment and the accomplishment of organizational missions Being committed to the organization involves some activity from the individual towards self-identifying with it and wishing to stay as a member, in order to satisfy his or her interests and to facilitate the accomplishment of the organizational missions. This article has adopted the affective commitment concept of Mowday, Porter and Steers (1979), which emphasizes the nature of the individual's identification process with organizational objectives and values, and has used the reduced scale proposed by Bastos (1994). It has focused on the organizational commitment of civil servants in the areas of health, education and safety. The results have indicated that the modified instrument allows the identification of the employee's commitment. This commitment is linked to the perceived organizational mission and not to the real organizational mission. Higher levels of commitment were found within safety employees, when compared to those from the health and education service areas.

\section{Introdução}

Becker (1992), ao rever estudos sobre comprometimento no trabalho, afirma existirem dois aspectos comumente salientados: os focos (organização, carreira e sindicatos, por exemplo) e as bases de comprometimento (afetiva, instrumental, normativa, entre outras). Os focos podem funcionar como alvos dos vínculos estabelecidos pelo trabalhador e as bases se referem à natureza ou aos motivos que levam ao comprometimento.

Bastos (1994) faz uma revisão sobre comprometimento com a organização e constata uma diversidade de definições associadas às operacionalizações do referido constructo. Ele aponta a existência de cinco vertentes de pesquisa, que se baseiam nos enfoques comportamental, normativo, afetivo, calculativo e autoridade no contexto de trabalho.

Na vertente atitudinal/afetiva, Mowday, Porter e Steers $(1979,1982)$ definiram o constructo enfatizando a natureza do processo de identificação do indivíduo com os objetivos e valores da organização. Para definirem o constructo, eles utilizaram três dimensões básicas: forte crença e aceitação dos valores e objetivos da organização; forte desejo de manter o vínculo com a organização; e intenção de se esforçar em prol da organização. As variáveis utilizadas para explicar o comprometimento consistem em características pessoais, características do trabalho, experiências no trabalho e 
"estados do papel" (o que é esperado do sujeito e coincidente com as realizações esperadas).

A vertente instrumental, também denominada calculativa, continuação e side-bets, concebe o comprometimento como uma função das recompensas e custos associados por estar na condição de integrante da organização - o indivíduo se mantém engajado por avaliar que os custos associados à sua saída são mais altos do que os benefícios, ou seja, ele permanece na organização porque necessita permanecer.

No enfoque sociológico está integrado o conceito de consentimento segundo o qual a organização de trabalho oferece escolhas reais aos trabalhadores, mesmo que de forma restrita. Assim, as instituições ${ }^{1}$ são enfatizadas como reguladoras e modeladoras dos conflitos sociais, diminuindo o efeito de fatores externos como escola, religião e família na produção.

A vertente da autoridade no contexto de trabalho, proposta por Halaby (1986, citado por Bastos, 1994) define o vínculo do trabalhador em termos das relações de autoridade que embasam o controle do empregador e a subordinação dos trabalhadores.

O enfoque normativo se baseia na estrutura das atitudes e do seu poder preditivo em relação ao comportamento, conceitualizando o comprometimento como o "conjunto de pressões normativas internalizadas pelo indivíduo para que se comporte congruentemente como os objetivos e interesses da organização" (Bastos, 1994:51). Há, assim, uma tentativa de integrar as pressões internalizadas (plano de análise individual) e os valores e normas partilhados associados às crenças instrumentais (plano de análise organizacional).

A última vertente - comportamental ou da consistência cognitiva considera que a avaliação de comprometimento pelo trabalhador é feita para manter a consistência entre os seus comportamentos e as suas atitudes.

Apesar de não haver consenso sobre o constructo de comprometimento organizacional, a literatura apresenta amplo predomínio da concepção afeti-

\footnotetext{
${ }^{1}$ Neste artigo, as palavras organizações e instituições são utilizadas como sinônimos. Todavia, ressaltamos que, numa dimensão sociológica, instituição tem a função de promover valores ou estabilidade social, coesão e integração, ao passo que a organização refere-se a um instrumento de trabalho racional concebido para a mobilização e a coordenação de esforços no cumprimento de propósito específico. Basicamente, o processo de institucionalização de uma organização implicaria infundir valores, além das exigências técnicas da tarefa. Assim, de acordo com Souza (1996) "uma organização, ao institucionalizar-se, adquire sentido de função social, passa a ser aceita pela sociedade, estabelece um sistema de relações a ser seguido, torna-se influente em seu contexto".
} 
va. Isso ocorre juntamente com a preponderância do uso da escala OCQ (organizational commitment questionaire). A escala OCQ foi proposta em 1970 por Porter e Smith. Posteriormente, Mowday, Porter e Steers (1979) continuaram realizando estudos que utilizavam a escala. O mesmo ocorreu com outros estudiosos do comportamento, sendo que Mowday, Porter e Steers (1979) passaram a ser os autores mais amplamente citados quando se trata do tema em questão. A versão reduzida do instrumento foi, então, construída por Mowday, Porter e Steers (1982).

Na metaanálise realizada por Mathieu e Zajac (1990), foi encontrado um coeficiente $\alpha$ de Cronbach de 0,88 para a versão completa (15 itens) e de 0,85 para a versão reduzida (nove itens). Apesar da superioridade da confiabilidade e da validade discriminante do OCQ quando comparado com escalas que medem comprometimento sob a perspectiva instrumental ou calculativa, existem controvérsias quanto à sua estrutura fatorial. Tetrick e Farkas (1988) encontraram uma estrutura bifatorial para o comprometimento afetivo (fator 1 - comprometimento com os valores da organização e fator 2 - intenções comportamentais de permanência na organização). Todavia, eles identificaram estabilidade temporal crescente no decorrer do tempo apenas para o fator 1. Isso os levou a, além de recomendar novos estudos longitudinais, sugerir o uso da versão reduzida da OCQ (nove itens) tal como indicado por Mowday, Porter e Steers (1979), posto que os nove itens se relacionavam ao fator 1 , além de que o fator 2 não era previsível a partir de sua própria medida em período anterior.

No contexto brasileiro, Borges-Andrade, Afanasieff e Silva (1989) validaram a escala OCQ - versão completa, tendo encontrado um $\alpha$ de Cronbach de 0,86. Bastos (1994) utilizou a escala reduzida (nove itens), retirando os sete itens que mensuravam intenções comportamentais. $\mathrm{O}$ autor encontrou um $\alpha$ de Cronbach de 0,88, com eigenvalue de 6,133 e 22,7\% da variância explicada e $71 \%$ da comunalidade. Por esse motivo, o autor recomenda o uso da escala reduzida, posto que a mesma consegue avaliar o comprometimento organizacional afetivo sem incorporação dos aspectos relativos a intenções e tem um $\alpha$ maior em relação ao estudo de Borges-Andrade, Afanasieff e Silva (1989).

Borges-Andrade, Cameschi e Xavier (1990) e Borges-Andrade (1994) definiram modelos de investigações situando o comprometimento como variável dependente e 59 indicadores de papéis, características pessoais, grupo de trabalho, estrutura organizacional e ambiente externo como variáveis independentes. Investigaram as variáveis relacionadas ao comprometimento nos perfis meio e fim da Embrapa (Empresa Brasileira de Pesquisa Agropecuária). Os autores apontaram um distanciamento entre os segmentos meio e fim das 
organizações e, conseqüentemente, a necessidade de se comparar os antecedentes de comprometimento nesses segmentos em instituições públicas como a Embrapa.

Eles apontaram as seguintes diferenças entre meio e fim, no que se refere ao conjunto de preditores de comprometimento:

v ponto de vista organizacional - conjunto mais intrincado nos segmentosfim, pois além de se relacionar com aspectos motivacionais e de carreira, outras variáveis são bastante importantes (relacionamento no grupo, sistema de retribuição de benefícios psicossociais entre organização e empregado e o grau de investimento pessoal feito por esse indivíduo na empresa);

- ponto de vista ocupacional - apresentaram-se como preditores as variáveis pessoais, de papel organizacional e de percepção de ambiente externo. Características pessoais e de papéis organizacionais não foram fortes preditores no segmento-fim.

Em ambos os segmentos, três variáveis são preditoras muito poderosas: sistema de promoções justo, oportunidades de desenvolvimento ocupacional e status externo da instituição. São completamente distintas as variáveis de percepção de ambiente externo significativamente correlacionadas com comprometimento nos dois segmentos. Entre o pessoal de apoio à pesquisa (ocupação meio), a percepção da existência de alternativas de emprego apareceu negativamente correlacionada com comprometimento. No segmento-fim, há correlações positivas com preferências por organizações alternativas que ofereçam estabilidade e gozem de bom conceito.

(Borges-Andrade, Cameschi e Xavier, 1990:56)

Segundo Borges-Andrade (1994), algumas variáveis significativas unem os segmentos meio e fim: justiça no sistema de promoções e oportunidades de desenvolvimento ocupacional. Outros aspectos moderadamente correlacionados foram: dificuldade de ingresso na empresa, status externo da mesma, satisfação com o relacionamento com colegas e interesse pelas atividades realizadas. Além disso, os principais antecedentes de comprometimento nos estudos brasileiros fortalecem as explicações que enfatizam as trocas indivíduoorganização, parecendo ser o comprometimento uma resposta do indivíduo a organizações que fornecem suporte para o alcance dos objetivos de crescimento e desenvolvimento pessoal e profissional, em um contexto de eqüidade no tratamento de seus recursos humanos. O autor conclui seu artigo fazendo algumas ressalvas, entre elas a de que há necessidade de ampliar a variedade 
de tipos de organizações públicas participantes do estudo, o que foi feito com a pesquisa ora realizada.

Quando não se separa a organização em meio e fim, o autor aponta o predomínio de variáveis organizacionais, ressaltando a existência de duas variáveis preditoras significativas: desenvolvimento ocupacional na instituição e imagem externa da organização. Todavia, a separação em segmentos meio e fim produz modelos preditivos distintos, e nos segmentos-fim há duas similaridades: status da organização e experiência gerencial anterior estão correlacionadas com comprometimento.

Bastos (1994:74), lidando também com a perspectiva afetiva do comprometimento organizacional, buscou "identificar fatores que expliquem níveis diferenciados de comprometimento organizacional entre trabalhadores de distintos grupos ocupacionais e entre os que atuam nos segmentos público e privado da administração". Na pesquisa foi comparado o comprometimento nos setores público e privado e analisados os determinantes de comprometimento organizacional em distintos grupos ocupacionais.

A maior parte da variabilidade de comprometimento foi explicada pelo conjunto de variáveis organizacionais (política de promoção explica 32,9\% da variância; políticas organizacionais de treinamento, 3,7\%; remuneração, $3,6 \%$ ), seguida de características do trabalho executado (escopo do trabalho, $7,3 \%$ da variância) e, seqüencialmente, de variáveis funcionais/carreira do trabalhador (estágio de carreira, ocupação) e de variáveis pessoais (centralidade do trabalho na vida, 1,5\% da variância).

Ao analisar os determinantes de comprometimento nos setores público e privado, Bastos (1994) identificou que o modelo explicava 47,8\% da variância de comprometimento nas empresas públicas, tendo como principais preditores: política de promoção ( $26,7 \%$ da variância), nível em que as expectativas que tinha ao ingressar na organização foram atendidas, idade do primeiro emprego e centralidade do trabalho. Já nos órgãos da administração pública direta, o modelo explica $67 \%$ da variabilidade, apresentando como principais preditores: avaliação da política de treinamento (49,3\% da variância), promoção, coordenação dos trabalhos intra e interequipes. Apenas os resultados da pesquisa na administração pública direta e indireta foram aqui apresentados em virtude de sua importância no escopo deste artigo.

Goldstein e Gilliam (1990) acreditam que a maioria das empresas onde os homens trabalharão no futuro estará envolvida com prestação de serviços. LaPalombara (1963) já enfatizara a necessidade de estudo no setor público pelo fato de ele influenciar quaisquer tipos de transformações no desenvolvimento social, econômico ou político de um país. Levando em conta tais pers- 
pectivas, este artigo foi realizado com base em estudo em instituições públicas cuja missão fundamental deveria ser a prestação de serviços, especificamente nas áreas que lidam diretamente com o público.

Este artigo amplia a investigação brasileira de comprometimento organizacional afetivo entre servidores públicos, mas numa direção distinta dos estudos já citados aqui. Assim, ao invés de incorporar um número amplo de variáveis num modelo preditivo, decidiu-se priorizar a questão da congruência entre as missões organizacionais (real e percebida) e das diferenças nos níveis de comprometimento entre servidores da saúde, educação e segurança, posto que as mesmas se configuram como direito do cidadão e obrigação do Estado.

Desde sua primeira definição, o conceito de comprometimento organizacional afetivo esteve vinculado à idéia de uma missão (que integraria objetivos e valores) da organização com a qual o indivíduo se identificaria. Essa identificação, no entanto, passa necessariamente pela existência de uma missão claramente definida e que seja conhecida pelos seus membros. Contudo, missões podem estar especificadas, mas serem percebidas de outra forma pelos indivíduos. Não foram encontrados, na literatura existente, estudos de comprometimento organizacional que explorasse tal questão.

\section{Método}

\section{Caracterização da amostra}

\section{Organizações participantes}

Neste artigo foram consideradas prestadoras de serviço as organizações cujas atividades estavam diretamente ligadas ao atendimento de direitos sociais estabelecidos constitucionalmente: moradia, alimentação, educação, saúde, cultura, lazer, transporte, segurança e assistência social. Das instituições responsáveis pelo atendimento a esses direitos sociais, foram selecionadas as do Distrito Federal que atendiam a esses direitos sociais que eram tipicamente dever do Estado. De acordo com Flauzino (1999:134-135):

v saúde - prestação de serviços de saúde física, mental e social nos níveis primário, secundário e terciário à população (hospitais e centros de saúde);

v educação - ensino sistemático e continuado em instituições escolares, promovendo o desenvolvimento intelecto-psico-socioambiental e atendimento 
às necessidades básicas dos alunos no período da infância e adolescência (escolas de $1^{\circ}$ e $2^{\circ}$ o graus);

v segurança - envolve o desenvolvimento de atividades de fiscalização, vigilância e combate de situações que coloquem em risco a integridade e a vida da população (órgão militar).

Apesar de restringir a quantidade de serviços prestados, foi mantida uma variação nos tipos de serviços categorizados como direitos sociais de dever do Estado, a fim de garantir a variabilidade da amostra. Assim, a cada dever correspondia uma organização representante.

Devido ao "gigantismo" das instituições participantes do estudo, houve necessidade de se estabelecer critérios mais específicos para a escolha das "partes" da organização que participariam da amostra. Foram eles: agrupamento das cidades por proximidade regional baseado na recenticidade de fundação de algumas cidades-satélites do Distrito Federal e do fracionamento das instituições próximas a essas cidades; a quantidade de habitantes de cada cidade (que indicou o quanto poder-se-ia agrupar as cidades), pois deveria haver um equilíbrio da quantidade de habitantes entre os agrupamentos de regiões.

A adoção dos critérios proximidade regional e tamanho da população resultou em cinco agrupamentos como mostra a tabela $1 .^{2}$

Tabela 1

Agrupamento de cidades onde as instituições prestam serviços

\begin{tabular}{|llc|}
\hline Grupo & \multicolumn{1}{c|}{ Cidades } & \% de participantes \\
\hline Grupo 1 & $1,2,3,4,5,6$ & 44,8 \\
Grupo 2 & $7,8,9,10,11,12,13$ & 12,9 \\
Grupo 3 & 14,15 & 14,3 \\
Grupo 4 & 16 & 13,6 \\
Grupo 5 & $17,18,19$ & 14,4 \\
\hline
\end{tabular}

Fonte: Flauzino, 1999:135.

\footnotetext{
${ }^{2}$ As análises realizadas neste artigo não avaliaram as diferenças entre os agrupamentos de cidades devido a conflitos políticos intensos ainda vividos, em virtude das eleições no Distrito Federal ocorridas à época da pesquisa.
} 
A fim de aumentar a precisão das estimativas das características da totalidade da população, a amostra foi estratificada selecionando-se setores que representavam cada agrupamento de cidades e que realizavam trabalhos substancialmente diferentes. Em seguida, foi sorteado aleatoriamente um dos setores para que representasse seus assemelhados e, em seguida, calculado o percentual de servidores de cada unidade em relação ao número total de servidores da amostra total da organização.

O maior percentual do grupo de cidades 1 , que pode ser visto na tabela 1, foi por essa região ter maior diversificação de unidades especializadas (um hospital central, um materno-infantil etc). E também pela disponibilidade de aplicação coletiva e pelo maior número de voluntários a participarem da pesquisa. Foi permitida a participação de todos os respondentes que se dispuseram a fazê-lo, para evitar que os participantes pensassem que eles haviam sido selecionados por outros motivos que não o de que possuírem os pré-requisitos para responderem o instrumento. A tabela 2 apresenta a amostragem das instituições com as principais informações sobre elas.

Tabela 2

Amostragem das instituições

\begin{tabular}{|c|c|c|c|c|c|}
\hline \multirow[b]{2}{*}{ Organização } & \multicolumn{5}{|c|}{ Respondentes } \\
\hline & № & $\begin{array}{c}\text { \% de } \\
\text { devolução }\end{array}$ & $\begin{array}{c}\% \text { da amostra } \\
\text { total }\end{array}$ & $\begin{array}{c}\text { Tipo de } \\
\text { prestação de } \\
\text { serviços }\end{array}$ & $\begin{array}{l}\text { Procedimento } \\
\text { de coleta }\end{array}$ \\
\hline Organização 1 & 371 & 93 & 41,22 & Segurança & Aplicação coletiva \\
\hline Organização 2 & 266 & 51 & 29,56 & Educação & $\begin{array}{l}\text { Entrega de } \\
\text { questionários por } \\
\text { coordenadores } \\
\text { pedagógicos e } \\
\text { aplicação coletiva }\end{array}$ \\
\hline Organização 3 & 263 & 52 & 29,22 & Saúde & Aplicação individual \\
\hline
\end{tabular}

Fonte: Adaptado de Flauzino (1999:136).

\section{Respondentes participantes}

Participaram da amostra 902 respondentes que tinham o $2^{\circ}$ grau completo, desempenhavam atividades caracterizadas como atividades-fim da organiza- 
ção, ${ }^{3}$ pertenciam à organização há pelo menos dois anos; estavam inseridos em seu quadro de empregos permanentes e estavam trabalhando na organização no dia da coleta de dados (desde que, no momento da pesquisa, não estivessem prestando serviços de emergência à população). O penúltimo prérequisito foi estabelecido por ser a cultura propriedade de uma unidade social estável, apenas onde existe um grupo definível com uma história significante formada no decorrer do tempo (Schein, 1985, 1990). A participação foi voluntária dada a natureza do tema e da necessidade de os sujeitos darem respostas que correspondessem ao que realmente pensavam sobre a instituição.

Dos 902 respondentes, 371 pertenciam a órgão militar, 266 a instituição educacional e 265 a instituição de saúde, sendo 59\% do sexo masculino e 40\% do sexo feminino. Com relação a idade, a maior parte estava na faixa de 20 a 40 anos (77\%). Considerando o grau de escolaridade, metade dos sujeitos possuía o 2 grau completo, $24 \%$ tinham curso superior completo e $14 \%$ com cursos de especialização após o curso superior.

As variáveis funcionais investigadas neste artigo consistiram em cargo de chefia (ter tido ou não chefia) e o tempo em que a chefia foi exercida. Como pode ser visto, dos $21 \%$ de sujeitos que exercem ou exerceram chefias, a maioria (44\%) o fez por um período de quatro a seis anos, seguida por seis a oito anos (33\%) e por oito a dez anos (15\%).

\section{Instrumentos}

Os instrumentos utilizados na pesquisa foram escala de comprometimento organizacional afetivo (Bastos, 1994) e os instrumentos para identificação de missão organizacional propostos por Gilbert (1978).

O instrumento para a identificação do comprometimento organizacional afetivo foi uma escala tipo Likert de sete pontos, composta por nove itens $(\alpha=0,88)$. Isso teve duas razões básicas: $\mathrm{o}$ instrumento de formato reduzido apresenta um $\alpha$ de Cronbach superior ao da versão completa da escala e os nove itens da escala OCQ reduzida se relacionam mais ao compartilhamento de objetivos e valores da organização, o que era objeto de interesse da pes-

\footnotetext{
${ }^{3}$ Borges-Andrade (1994:50) assim diferencia segmento-meio e segmento-fim: "entende-se por segmento-meio aquele que está mais distante da consecução dos objetivos da instituição, seja em termos ocupacionais (...) ou em termos organizacionais (...). O segmento-fim, por outro lado, é o que tem ocupações (...) ou está lotado em setores organizacionais (...) próximos da consecução dos objetivos institucionais".
} 
quisa e não inclui aspectos relativos a intenções de rotatividade, que de certa forma prejudicam a concepção de comprometimento que se queria enfatizar.

A identificação das realizações esperadas no nível político foi feita por intermédio das especificações dos resultados a serem alcançados pelas instituições de segurança, saúde e educação estudadas. Aplicando-se entrevista e analisando-se documentos, foi feito o levantamento das missões organizacionais, ${ }^{4}$ seguindo-se as regras descritas por Gilbert (1978). Após a identificação das realizações esperadas no nível político, as mesmas foram submetidas ao Teste Acorn (ver quadro). Nele, as respostas devem ser dadas pelo pesquisador e baseadas em dados obtidos por intermédio de entrevistas (roteiro traduzido por Flauzino, 1991 e publicado por Flauzino e Milani, 2000) em consonância com as orientações de Gilbert (1978) e análise de documentos da e sobre a instituição. Para que haja uma caracterização das reais missões da organização (referente aos seus verdadeiros objetivos), as respostas a todas as questões devem ser afirmativas. Essas perguntas também são úteis para verificar se as realizações esperadas foram realmente identificadas e se a missão foi formulada de modo a ser facilmente entendida.

\section{Teste Acorn}

\begin{tabular}{|ll|}
\hline Inicial & \\
\hline A & São realizações esperadas (accomplishments) e não apenas comportamentos ou atividades? \\
C & Os membros têm o maior controle sobre isto? \\
O & É um objetivo global e não apenas um específico? \\
R & Esta missão pode ser reconciliada com outros objetivos? \\
N & Pode ser medida e expressa em números? \\
\hline
\end{tabular}

Fonte: Flauzino (1999:144, adaptado de Gilbert, 1978).

\section{Procedimentos de coleta e análise de dados}

Autorizada a participação das instituições selecionadas por seus responsáveis legais, os ocupantes dos cargos de interesse foram contatados por meio de

\footnotetext{
${ }^{4}$ Baseado na teoria de Gilbert (1978), foi construído por Flauzino (1999) um guia de identificação das missões organizacionais, que foi utilizado juntamente com análises documentais e entrevistas semiestruturadas. Ressaltamos que o mesmo faz parte de um guia mais amplo utilizado para o diagnóstico de problemas específicos nas instituições. Maiores detalhes podem ser vistos em Flauzino (1999).
} 
suas chefias. A coleta de dados foi iniciada com a realização de análises documentais (relatórios, controles e jornais internos, processos, correspondências, além de publicações externas relacionadas à organização), que indicaram as pessoas-chave da instituição que deveriam ser entrevistadas. Em seguida, foram realizadas entrevistas semi-estruturadas (com as pessoas-chave) baseadas no levantamento de missões organizacionais (Flauzino, 1999). Após a análise documental e a execução das entrevistas, foi especificada a missão da instituição por meio da análise qualitativa dos dados. A seguir, foi montado o Teste Acorn para verificar se a missão foi identificada corretamente, constituindo-se a missão real da mesma.

Numa segunda etapa, foi aplicada à amostra anteriormente definida aqui a escala de comprometimento organizacional afetivo. Ao final do instrumento, foi solicitado aos sujeitos que descrevessem brevemente as principais missões organizacionais da instituição na qual trabalhavam. Inicialmente foi planejada a aplicação coletiva do instrumento. Mas dificuldades operacionais, como agrupar respondentes, tempo despendido para agrupá-los (mesmo que de forma alternada) e disponibilidade apresentada pela organização e pelos aplicadores do instrumento, levaram à escolha de três tipos de procedimentos de coleta de dados: aplicação coletiva, entrega e recolhimento de questionários por aplicadores da pesquisa e por coordenadores pedagógicos. Ao recolher os questionários respondidos, eram examinadas as lacunas de preenchimento deixadas e solicitado o preenchimento. A recusa dos respondentes em fazê-lo resultou na desconsideração de suas respostas quando o índice de dados ausentes superava 10\%.

Na terceira etapa, as missões especificadas pelos respondentes na questão aberta do instrumento geral foram submetidas a uma análise de conteúdo, resultando no estabelecimento de categorias de missões percebidas.

$\mathrm{Na}$ quarta etapa, as categorias das missões percebidas pelos respondentes foram comparadas à missão real (identificada na primeira etapa). A seguir, as missões percebidas foram classificadas em duas categorias maiores: missão percebida coincidente com a missão real; e missão percebida não coincidente com a missão real.

A análise dos resultados foi feita em duas etapas: uma qualitativa e outra quantitativa. A análise qualitativa ocorreu quando da análise de documentos e entrevistas, e ao realizar-se a análise de conteúdo das missões organizacionais relatadas pelos respondentes ao final do instrumento de coleta de dados. Já a quantitativa foi efetuada por meio de análises estatísticas descritivas e multivariadas utilizando-se o software SPSS for Windows, a fim de processar os dados contidos nos instrumentos por meio da análise fatorial da escala de comprometimento organizacional afetivo. 
Basicamente, as análises qualitativa e quantitativa buscaram abranger várias formas de análise de dados e compatibilizá-las, já que os mesmos foram obtidos por intermédio de métodos de coleta diferenciados. O uso de métodos de coleta e de análise diversificados e complementares se justifica pela necessidade de se conseguir captar a complexidade existente nas organizações e, conseqüentemente, entendê-las de forma mais completa e dinâmica.

\section{Resultados e discussão}

A análise quantitativa de dados foi iniciada com a codificação das respostas ao instrumento e à questão aberta contida no instrumento geral de coleta de dados. A seguir, ocorreu a preparação do banco de dados (SPSS for Windows, versão 8.0).

Uma análise preliminar dos dados foi realizada para verificar o atendimento aos pressupostos assumidos pela análise fatorial. Inicialmente, foram corrigidos erros de digitação e verificou-se se as médias e os desvios-padrão possuíam valores plausíveis e se os coeficientes de variação estavam bem acima de 0,0001 , o que garantiria pequena probabilidade de erros de arredondamento influenciarem os cálculos.

O percentual máximo de ocorrência de dados ausentes por item foi $3,59 \%$, e o percentual médio de $1,34 \%$. Tais percentuais levaram à decisão de substituir os valores ausentes pela média. Todavia, a transformação utilizada para aproximar essa variável da normalidade não resultou em mudanças significativas que justificassem seu uso.

Na pesquisa dos valores discrepantes, por intermédio da distância Mahalanobis em $\mathrm{p}<0,001\left(\mathrm{gl}=73, \chi^{2}=112,317\right.$ ), foram identificados 10 casos extremos multivariados, sendo cinco deles também valores discrepantes univariados. Os instrumentos dos 10 respondentes foram eliminados da amostra por apresentarem padrões estereotipados de respostas. Todos eles deram respostas extremadas (1 ou 7 e 0 ou 6 , dependendo da escala) ao instrumento.

Quanto ao tamanho da amostra, a razão de casos por variável foi de 102,22, o montante de 902 casos válidos, tendo sido respeitada a proporção mínima de sujeitos de cada instituição participante. Assim, o tamanho da amostra foi adequado para a realização de procedimentos estatísticos a serem utilizados.

A inspeção da linearidade e da homocedasticidade da amostra foi feita por meio das distribuições residuais e dos gráficos de dispersão bivariados, verificando-se a sua existência dentro dos limites adequados para a realização da análise fatorial. 
Os indicadores da fatorabilidade da matriz $\mathrm{R}$, usando a opção de extração Maximum Likelihood, foram os seguintes:

v a matriz correlacional possuía 69,44\% de correlações acima de 0,30 (em valor absoluto);

v a medida de adequação amostral Kaiser-Meyer-Olkin (KMO) de 0,89 considera a matriz "meritória" (mas bem próximo de "maravilhosa") para ser fatorada, como indicado pelos criadores da medida;

v o alto valor encontrado no Teste de Esfericidade de Bartlett $(2.952,30)$ aliado à baixa significância (zero) indica que a matriz não é identidade e, portanto, é fatorável;

- o determinante muito próximo de zero $(0,033)$ é indicativo de que a matriz pode ter apenas um fator ou comportar fatores de segunda ou mais ordens;

v as medidas de adequação amostral MSA variaram de 0,77 a 0,93 - uma se encontrava na faixa de 0,75 a 0,80 , quatro na de 0,85 a 0,90 e quatro na de 0,90 a 0,95 , o que também indica fatorabilidade da matriz.

Portanto, a maioria dos indicadores apontou que a matriz correlacional dos dados amostrais é adequada para ser submetida à análise fatorial. Do mesmo cálculo utilizando-se a opção de extração anterior (Maximum Likelihood) foram obtidas as comunalidades dos itens, que apontaram a não-colinearidade e não-singularidade entre as variáveis. Dois dos nove itens (eu realmente me interesso pelo destino da organização onde trabalho e eu sinto pouca lealdade para com a organização onde trabalho) apresentaram comunalidades inferiores a 0,30, e foram retirados da análise.

A estimativa da quantidade de fatores subjacentes à matriz foi realizada por meio da análise dos componentes principais (PCA - Principal Components Analysis). Juntamente com os critérios do eigenvalue $=1$ e da distribuição desses valores, a extração apontou a existência de apenas um fator, ou seja, a escala era unifatorial. Isso também foi confirmado por Bastos (1994) quando ele utilizou a escala reduzida no Brasil.

A extração PAF foi realizada com um único fator para verificar as cargas fatoriais. O cálculo da confiabilidade do fator foi de $\alpha=0,75$, sendo que a retirada do item COMPR8 (decidir trabalhar nessa organização foi um erro de minha parte) elevou o mesmo para 0,87 . Assim, decidiu-se pela exclusão desse item da escala. Os itens que permaneceram após a análise dos dados estão na tabela 3. 
Tabela 3

\section{Cargas fatoriais e comunalidades}

\begin{tabular}{|c|c|c|c|}
\hline Item & Carga & $\mathrm{h}^{2}$ & Descrição \\
\hline COMPR3 & 0,82 & 0,60 & Sinto orgulho dizendo que sou parte da organização \\
\hline COMPR 1 & 0,77 & 0,53 & Fico contente por optar por aqui na época da contratação \\
\hline COMPR5 & 0,74 & 0,55 & $\begin{array}{l}\text { Refiro-me à organização como grande instituição para a qual é ótimo } \\
\text { trabalhar }\end{array}$ \\
\hline COMPR7 & 0,69 & 0,42 & Digo que esta é a melhor de todas as organizações para se trabalhar \\
\hline COMPR4 & 0,67 & 0,40 & $\begin{array}{l}\text { A organização inspira o melhor em mim para meu progresso no } \\
\text { desempenho do meu trabalho }\end{array}$ \\
\hline COMPR2 & 0,65 & 0,38 & Meus valores são similares aos da organização \\
\hline \multicolumn{4}{|c|}{ Eingenvalue $=3,93$} \\
\hline \multicolumn{4}{|c|}{ \% da variância total $=56,1$} \\
\hline \multicolumn{4}{|c|}{ Alpha de Cronbach $=0,87$} \\
\hline
\end{tabular}

Fonte: Flauzino, 1999:160.

A composição final do instrumento de medida de comprometimento foi marcada pela permanência dos itens que possuíam caráter afetivo mais marcante. Assim, itens envolvendo também aspectos cognitivos (COMPR6 - interesse pelo destino da organização e COMPR8 - decisão de trabalhar na organização) foram eliminados do instrumento.

Isso pode ser evidenciado quando se compara os itens COMPR8 (decidir trabalhar nessa organização foi um erro de minha parte) e COMPR5 (Eu me sinto contente por ter escolhido essa organização para trabalhar). COMPR5, que permaneceu no instrumento, envolve sentir contentamento pela escolha (tipicamente afetivo) enquanto COMPR8 envolve tomar decisão (possui aspectos afetivos e cognitivos). Julgar uma decisão tomada envolve tentar minimizar as dissonâncias cognitivas com relação a ela e, muitas vezes, isso é feito ou enviesando fatos ou desconsiderando fatos e informações que trabalham negativamente com a alternativa escolhida.

COMPR6 (eu realmente me interesso pelo destino da organização onde trabalho) envolve aspectos afetivos (gostar da organização, sentimento de querer preservá-la e de prestar bons serviços à população) e cognitivo-calculativo (caso a organização se desintegre, ele sofrerá perdas financeiras, ficará desempregado e a população não terá mais acesso ao serviço gratuito que é obrigação do Estado). 
Já o item COMPR9 (eu sinto pouca lealdade para com a organização onde trabalho) possui conseqüências inequívocas: para ser leal com a organização, deve haver retidão para com ela. Mas, a lealdade dos servidores públicos das três áreas estudadas possui duas vertentes: ser leal com as decisões e procedimentos estabelecidos pelos representantes da instituição, mesmo que eles acarretem prejuízos à população; e ser leal com a população, prestando-lhe serviços adequados na hora certa, mesmo que para isso sejam violados regras, procedimentos e ordens estabelecidas pelos dirigentes. Assim, para os executores da atividade-fim das instituições estudadas, ser leal pode eventualmente até possibilitar o prejuízo daqueles para os quais ela foi criada. Talvez, por isso, esse item tenha se desagregado do comprometimento afetivo com a organização. A separação da lealdade nesses dois aspectos pode ser derivada do contato direto que esses profissionais possuem com a população.

Portanto, podem existir duas razões básicas para os itens COMPR6, COMPR8 e COMPR9 terem se desagregado do instrumento utilizado:

v caráter afetivo esteve associado ao cognitivo nos itens COMPR8 e COMPR6;

- lealdade com a organização poderia implicar prejuízo do alcance de sua missão (COMPR9).

Assim, percebe-se que o comprometimento dos servidores públicos, executores da atividade-fim, aqui mensurados é caracteristicamente de natureza afetiva.

Ao analisar o comprometimento organizacional afetivo nos grupos 1 ("missão organizacional percebida" coincidente com a "missão real") e 2 ("missão organizacional percebida" não coincidente com a "missão real"), nota-se a não-existência de diferenças significativas nas médias dos dois grupos, não havendo discrepâncias de comprometimento nos grupos de respondentes em que existem consistências e inconsistências entre missões reais e missões percebidas (vide tabela 4). Assim, o comprometimento afetivo com a organização parece ser independente da percepção da "missão real" da instituição pelos indivíduos. O comprometimento organizacional, portanto, poderia estar unicamente baseado na crença a respeito da missão e não naquela que efetivamente está formulada. Evidentemente, uma explicação alternativa para esses resultados poderia ser a existência de problemas na análise qualitativa dos dados referentes às missões real e percebida. 
Tabela 4

Grau de comprometimento organizacional afetivo dos grupos 1 e 2

\begin{tabular}{|ccccccc|}
\hline Grupo & Média & Desvio-padrão & Erro-padrão & $\mathbf{t}$ & $\mathrm{df}$ & Significância \\
\hline 2 & 4,41 & 1,24 & 0,05 & $-1,86$ & 896 & 0,06 \\
1 & 4,58 & 1,27 & 0,07 & $-1,85$ & 622 & 0,07 \\
\hline
\end{tabular}

Fonte: Flauzino, 1999:170.

\section{Comparando as organizações de saúde, educação e segurança}

A tabela 5 apresenta as médias, os desvios-padrão, os erros-padrão e os valores de $\mathrm{F}$ relativos ao comprometimento organizacional afetivo nas três instituições. Esses dados foram obtidos por meio da realização da Anova (oneway).

Tabela 5

Comparação do comprometimento organizacional afetivo por instituição

\begin{tabular}{|lccccc|}
\hline Instituição & Média & $\begin{array}{c}\text { Desvio- } \\
\text { padrão }\end{array}$ & $\begin{array}{c}\text { Erro- } \\
\text { padrão }\end{array}$ & F & Significância \\
\hline Instituição de segurança & 4,85 & 1,24 & 0,06 & & \\
Instituição de educação & 4,20 & 1,23 & 0,08 & & \\
Instituição de saúde & 4,20 & 1,14 & 0,07 & & \\
Amostra total & 4,47 & 1,25 & 0,04 & 31,32 & 0,0001 \\
\hline
\end{tabular}

Fonte: Flauzino, 1999:172.

Foi constatada diferença significativa entre as médias das três instituições $(\mathrm{p}=0,0001)$ no que se refere ao comprometimento organizacional afetivo. Por meio do Teste de Tuckey, verificou-se que a média da instituição de segurança é significativamente maior do que as das outras instituições $(\mathrm{p}=0,0001)$, não existindo diferenças significativas entre as médias das instituições de educação e saúde. Logo, existiria maior comprometimento organizacional afetivo na instituição de segurança do que nas demais.

$\mathrm{Na}$ análise do comprometimento organizacional afetivo, observou-se leve concordância quanto à percepção de que os respondentes se comprometem afetivamente com a organização à qual pertencem (tabela 5). Mas, quando se analisa as instituições separadamente, constata-se que a média da instituição de segurança é bem maior que as das instituições de educação e saúde, e as médias destas não diferem significativamente entre si. Isso pode 
ser devido ao exercício das atividades do corpo de bombeiros estar intrinsecamente relacionado ao cumprimento da missão da corporação. Ou seja, apesar do exercício das atividades obedecer uma estrutura hierárquica fortemente estabelecida, há também um relacionamento altamente complexo entre as diversas especializações no grupo dos bombeiros, pois a falta de integração dos mesmos no trabalho colocaria em risco, de imediato, não só a vida da população, mas também as suas próprias.

Além disso, o maior nível de comprometimento da instituição de segurança pode ter sido devido à menor escolaridade dos bombeiros executores da atividade-fim (geralmente, $2^{\circ}$ grau completo) em relação às instituições de saúde e educação. Nas últimas, há um predomínio de profissionais de nível superior. A pesquisa de Bastos (1994), realizada sobre o comprometimento dos empregados nos âmbitos público e privado, aponta um menor nível de comprometimento dos profissionais de nível superior com a organização quando eles trabalham em instituições públicas, dado consistente com os aqui encontrados.

Analisando-se uma pesquisa mais ampla (Flauzino, 1999), identificouse um padrão cultural comum do serviço público da área-fim. Contudo, alguns indicadores apontaram a existência de subculturas nas instituições pesquisadas, incluindo-se aqui o comprometimento organizacional afetivo. No estudo dessa variável, notou-se que os servidores das três instituições o percebem como existente. Entretanto, há uma percepção diferenciada quando se considera instituição militar e não-militar (na primeira, há maior percepção da variável).

O elevado nível de comprometimento organizacional afetivo dos servidores da instituição de segurança pode ser devido, ainda, ao comprometimento que os mesmos têm com o caráter ideológico da instituição e não com a mesma em sua integralidade.

Analisando-se a maior freqüência modal das respostas dos sujeitos da amostra total verifica-se que há um comprometimento moderado. Todavia, a análise de escores modais por item aponta uma discrepância no item da organização ser a melhor de todas para se trabalhar (COMPR7). Assim, apesar de existir comprometimento afetivo com a organização, ela não é percebida por $43,5 \%$ dos respondentes como a melhor alternativa de local de trabalho em contraposição aos que a consideram como tal (32\%).

O comprometimento organizacional afetivo na instituição de saúde se diferenciou do encontrado na instituição de segurança, embora isso possa ter ocorrido em função do nível de escolaridade. O idealismo de auxílio à população carente e os benefícios oferecidos pela instituição podem fazer com que 
os servidores permaneçam nessa organização. Contudo, o fato de não perceberem a instituição como a melhor para se trabalhar leva os profissionais de saúde a duplicarem suas cargas de trabalho em outras organizações, o que pode levar a maiores riscos de desgaste desses profissionais e a aumento dos riscos de transmissões de infecções ocasionados pelo trânsito entre diferentes instituições hospitalares.

\section{Conclusão}

Apesar de ter sido encontrado moderado comprometimento afetivo dos servidores públicos, é necessária a ampliação da quantidade e diversidade de organizações estudadas para haver a identificação de um padrão nacional e não apenas restrito a uma unidade da federação. Isso permitiria um aumento de variabilidade e, conseqüentemente, de estabilidade dos achados, formando um quadro mais fidedigno do comprometimento organizacional afetivo do servidor público brasileiro.

Outro aspecto que necessita ser analisado é a lealdade. O item relativo a essa variável foi eliminado quando da análise fatorial. Em estudos brasileiros anteriores esse item se agregava aos demais. A eliminação do item pode estar refletindo a crescente diminuição da lealdade dos empregadores em relação aos trabalhadores quando a preocupação consiste em reduzir custos. Como o comprometimento empregador-trabalhador é permeado por relações de troca, a lealdade do servidor com relação à organização também está reduzida.

Sabe-se que a redução de custos é um imperativo diante do fenômeno da globalização. No entanto, é preciso ser repensada a forma como tem sido feita. Mesmo que o custo financeiro seja reduzido, a quebra da lealdade pode produzir, em futuro próximo, custos maiores como elevação da taxa de rotatividade (aposentadoria imediatamente após o direito adquirido, o que é descapitalizador especialmente para as universidades públicas brasileiras) e emissão de comportamentos disfuncionais que desconsiderem princípios morais (furtos, descaso ou depredação do patrimônio, entre outros).

Assim, pode ser questionado: é possível a reconquista dos princípios morais (muitas vezes, denominados, erroneamente, éticos), tão propagada dentro das organizações, se há uma violação do sentimento de lealdade? É possível confiar na existência de uma relação de troca se uma das partes viola seus acordos? São necessários posicionamentos críticos diante desse fenômeno, analisando as suas conseqüências psicológicas e morais. Quando se reflete sobre essas questões, algumas dúvidas surgem: caso haja um incremento na 
diminuição da lealdade que se estenda das organizações administradas pelo Estado para a população (como já vem ocorrendo em alguns casos), qual seria o papel dele na prestação de serviços à população e na proteção do cidadão brasileiro? Ficam as questões para reflexão.

\section{Referências bibliográficas}

BASTOS, A. V. B. Comprometimento no trabalho: a estrutura dos vínculos do trabalhador com a organização, a carreira e o sindicato. 1994. 314f. Tese (Doutorado) — Instituto de Psicologia, Universidade de Brasília, Brasília.

BECKER, T. E. Foci and bases of commitment. The American Journal of Sociology, v. 66, n. 1, p. 32-40, 1992.

BORGES-ANDRADE, J. E. Comprometimento organizacional na administração pública e em seus segmentos meio e fim. Temas em Psicologia - Psicologia Social e Organizacional, n.1, p. 81-103, 1994.

; AFANASIEFF, R. S.; SILVA, M. S. Mensuração de comprometimento organizacional em instituições públicas. In: REUNIÃO ANUAL DE PSICOLOGIA,19., 1989, Ribeirão Preto. Anais... Ribeirão Preto: Sociedade de Psicologia de Ribeirão Preto, 1989.

; CAMESCHI, C. E.; XAVIER, O. S. Comprometimento organizacional em instituição de pesquisa: diferenças entre meio e fim. Revista de Administração, v. 25, n. 4, p. 29-43, 1990.

FLAUZINO, D. P. Uma aplicação da auditoria do desempenho proposta por Thomas F. Gilbert em um hospital universitário.1991. Dissertação (Mestrado) — Programa de Pós-Graduação em Psicologia, Universidade de Brasília, Brasília.

. Cultura e missão percebidas: uma análise organizacional no setor público. 1999. 218 f. Tese (Doutorado) — Instituto de Psicologia, Universidade de Brasília, Brasília.

GILBERT, Thomas F. Human competence: engineer worthy performance. New York: McGraw-Hill, 1978. 376p.

GOLDSTEIN, I. L.; GILLIAM, P. Training system issues in the year 2000. American Psychologist, v. 45, n. 2, p.134-143, 1990.

LAPALOMBARA, J. An overview of bureaucracy and political development. In: . Bureaucracy and political development. New Jersey: Princeton University Press, 1963. p. 3-33. 
MATHIEU, J. E.; ZAJAC, D. M. A review and meta-analysis of the antecedents, correlates, and consequences of organizational commitment. Psychologycal Bulletin, v. 108, n. 2, p. 171-194, 1990.

MOWDAY, R. T.; PORTER, L. W.; STEERS, R. M. Employee-organization linkages: the psychology of commitment, absenteeism, and turnover. New York: Academic Press, 1982.

; __ _ The measurement of organizational commitment. Journal of Vocational Behavior, n. 14, p. 224-247, 1979.

et al. Organizational commitment job satisfaction, and turnover among psychiatric technicians. Journal of Applied Psychology, n. 5, p. 603-609, 1975.

SCHEIN, E. H. Defining organizational culture. In: SHAFRITZ, J. M.; OTT, J. S. Classics of organizational theory. California: Brooks/Cole, 1985. 1990.

. Organizational culture. American Psychologist, v. 45, n. 2, p. 109-119,

SOUZA, E. C. L. de. Escolas de governo do Cone Sul: estudo institucional do Inap (Argentina) e da Enap (Brasil). 1996. 300f. Tese (Doutorado) — Flacso, Universidade de Brasília, Brasília.

TETRICK, L. E.; FARKAS, A. J. A longitudinal examination of the dimensionality and stability of the Organizational Commitment Questionaire (OCQ). Educational and Psychological Measurement, v. 48, p. 723-735, 1988. 